\title{
Sensory storage reconsidered
}

\author{
DENNIS H. HOLDING \\ University of Louisville, Louisville, Kentucky 40206
}

\begin{abstract}
Models of sensory storage appear to incorporate three features: capacity in excess of short-term memory, rapid decay of information, and an unprocessed trace as the storage medium. The evidence for each is examined in the visual and the auditory modes. The excess capacity hypothesis is rejected on the grounds that negative results are obtained when output interference and cue anticipation mechanisms are excluded. Rapid decay is seen as a minor effect which may not result from sensory storage. Limited trace storage appears to exist in the form of extremely brief sensory persistence, but applies only to normally attended stimuli; the pivotal concept of subsequent random access to a trace appears unsupported.
\end{abstract}

The notion of sensory storage was first made explicit as a feature of human information processing in tine model proposed by Broadbent (1957) to account for selective auditory attention. Since simultaneously presented stimuli must be reported successively, it was suggested that "incoming information may be held in a more temporary store at a stage previous to that of the selective operation [p. 205]." Information retained in a store prior to the filter was understood to decline with time in storage, in a manner similar to the properties later attributed to visual storage.

As Mackworth (1962) points out, an earlier example of the concept of the "memory after-image" was provided by Glanville and Dallenbach (1929) on the basis of data obtained from the tachistoscopic presentation of geometric and letter forms. However, these authors realize that the memory afterimage may not be a simple perceptual trace since, as one of their Ss reports, "the locus of the image did not change with a shift of his line of regard [p. 220]." The possibility is entertained that the memory afterimage is not an immediate datum but one of a mediated type which is dependent upon apprehension, and the possibility of "reimaging" is included with counting and adding as a form of mnemonic aid.

The direction taken by research into sensory storage during recent years, of course, derives principally from the work of Sperling $(1960,1963$; Averbach \& Sperling, 1961) and its elaboration by Neisser (1967). In the formulation of Sperling (1960), the hypothesis of visual information storage asserts that briefly exposed stimuli may be preserved by a visual image which persists after physical stimulation of the eye has ceased. The visual image decays rapidly over a period of time whose exact length depends upon subsidiary experimental conditions. It is assumed that a $S$ who receives a delayed instruction during the time that the visual image is available can read out information which he was not forwarned to select, almost as if he was scanning the original stimulus array, and that the information which can be recovered in this way represents a larger amount than can be accommodated by normal short-term memory.
The visual storage hypothesis has been rather rapidly absorbed into the information processing literature, and many researchers have assumed that the properties of the "icon" may be accepted as a foregone conclusion in explaining or predicting related phenomena. Rumelhart (1970) has constructed a mathematical model of input processing which incorporates these assumptions in a quantifiable form, together with the assumption that that masking prodaces erasure. Posner (1969) discusses the differences between his form of visual short-term memory, based on response time data to visually or symbolically identical letters, and the assumed properties of iconic storage. Wickelgren and Whitman (1970) do not question whether visual very short-term memory exists, but ask whether or not it is associative, despite the fact that only 8 of 17 Ss showed evidence of visual memory in pretests and 2 of the 8 selected Ss showed no effects in the main experiment. In fact, there appear to be good grounds for questioning the validity of the visual storage hypothesis in its original form.

The complexity of the visual information storage hypothesis has given rise to some confusion in the literature. For the present purposes, three main component hypotheses are distinguished: (1) the excess capacity hypothesis, which suggests that the visual image has a substantially larger storage capacity than has short-term memory; (2) the rapid decay hypothesis, which states that the amount of information which can be recovered declines over delay times of the order of $1 \mathrm{sec}$; (3) the trace storage hypothesis, which asserts that the information retained is held in a raw, unprocessed state which is both comprehensive and amenable to subsequent access. Each of these hypotheses may be considered independently. It is clearly possible to envision a model in which excess capacity is not dependent upon trace storage or rapid decay, or a model with trace storage but not excess capacity, or with rapid decay occurring for reasons unconnected with trace storage or excess capacity. The intention of the present paper is to review the evidence for each of these hypotheses, first in application to visual storage and, second, in their analogous form for auditory storage. 


\section{VISUAL STORAGE}

\section{Excess Capacity}

The hypothesis that more is stored than can be reported is a major theoretical innovation which provides the main justification for attempting to set visual storage apart from the normal memory span as a separate mechanism. The evidence for excess capacity derives from the comparison of whole with partial reports. In whole report, the $S$ recalls what he can from the entire display; in partial report, he recalls that part of the display indicated by a subsequent cue. If, as is hypothesized, the amount of information in visual storage exceeds what may be retained in a whole report, it is necessary to use the partial report as a sampling technique in order to estimate the capacity of the sensory trace. The number of items available to partial report is therefore multiplied by a factor relating the sample size to the size of the whole stimulus array in order to estimate the number of items potentially available.

With 12-letter arrays, sampled on a row-by-row basis in response to tonal cues immediately following the stimulus exposure, Sperling (1960) obtained an estimate of over nine letters available to partial report. This substantially exceeds the four or five normally given in whole reports with the same exposure parameters, providing prima facie evidence for sensory storage. Many subsequent experiments have shown essentially similar results, although usually with lower estimates of the amount available to partial report; the visual bar-marker results of Averbach and Coriell (1961) appeared appreciably higher but were obtained with simultaneous rather than subsequent cuing.

Using bar-marker cues in a circular display of Xs and Os, Eriksen and Steffy (1964) found delay effects which seemed inconsistent with visual storage. Steffy and Eriksen (1965) reached similarly adverse conclusions as a result of comparing preexposure with postexposure cues for the recognition of nonsense shapes. The earlier experiment has been criticized by Keele and Chase (1967), who argued that the exposure illumination was undesirably low and that the six items exposed were unlikely to exceed the memory span. In their own experiment, 10 letters and digits were displayed at three levels of illumination, one item at a time being cued for partial report. Some effect of partial report superiority appeared, due to two of the four Ss, at the lowest illumination, but even at the highest illumination level only $6 \frac{1}{2}$ items were estimated as available.

Von Wright (1968) provides further evidence of smaller differences between partial and whole report efficiency, comparing several kinds of partial report cue. With stimulus arrays of two rows each of four letters, cuing by row location again produced an estimate of $6 \frac{1 / 2}{2}$ letters available. Cuing by color gave under six, while cues requiring finer discriminations, based on differences in size or depth of gray, yielded estimates of less than five letters. With differences in letter orientation as cues, partial report estimates were equal to or less than the corresponding whole reports. If we compare these results with Sperling's (1960) failure to find partial report superiority for letter vs number cuing, the apparent conclusion is that selection from a visual image is more effective with spatial cues than with more obscure physical cues or with cues relying upon learned attributes. It should be noted, however, that it is also possible to view these variations in the effectiveness of cues as arising from differences in their susceptibility to preselection from a visual array, rather than as effects of selection from a later trace. It is possible for a $S$ to preset his attention for specific rows or columns in a way that is not possible for letters vs digits.

Clark (1969) has also shown a difference between row location and color cuing for Ss reporting on red, green, and yellow circles, although no figures are given for the estimated number of items available. Interpretation is difficult, since the probability of guessing an individual item appears to be at least 0.3 , which could give rise to substantial distortion of the results. Eriksen and Colegate (1971) also use a restricted stimulus ensemble, the letters $\mathrm{A}, \mathrm{H}, \mathrm{T}$, and $\mathrm{Y}$ occurring twice in each presentation. However, although their single indicator cue did not follow but was present throughout the entire exposure, only seven letters appeared to be available.

A further difficulty occurs in the experiment of Turvey and Kravetz (1970), where only the stimuli R, O, and $\mathrm{Z}$ were used in a comparison of cuing by location and by letter shape. This experiment and that of Doost and Turvey (1971) appear to provide the only recent evidence of an estimated storage capacity of greater than 10 letters. However, these figures might be viewed with reservation owing to the heavily repeated use of the same stimulus slides, although Turvey (1967) had found no apparent learning over repeated presentations of unprocessed stimuli. It will be remembered that Bricker and Chapanis (1953) once showed in another context that a right-wrong response measure may be inadequate; Ss to whom letters have been presented in a tachistoscope may acquire some information from the letters, although insufficient to yield accurate responses.

The main difficulty confronting all demonstrations of excess capacity is that all partial-whole comparisons are liable to two potent forms of artifact. The two mechanisms of cue anticipation and output interference both have the effect of producing an apparent superiority of partial over whole reports, cue anticipation by inflating the amount of information ostensibly sampled by partial reports and output interference by depressing the amount apparently available to whole reports. The existence of both of these effects has been verified experimentally in the context of tachistoscopic information presentation.

If a $\mathrm{S}$ anticipates the cue and looks at one of three rows, it is no longer legitimate to multiply his partial report score by 3 to estimate the letters available. It has 
been shown (Holding, 1970) by eliciting Ss' guesses as to which row is next to be cued that the number of letters in partial report is a direct function of the accuracy of cue anticipation. Guessing of cues is, of course, to be distinguished from the guessing of individual stimulus items, which will normally have little effect when there is a large stimulus ensemble and when items are scored for correctness in the correct location. The guessing of cues in a sequence of trials was in turn shown to vary with the statistical structure of the cue sequences, improving steadily from randomness through to complete predictability. Ss appear sensitive to quite small constraints upon randomness, such as are introduced by balancing the numbers of cues of each type used in a sequence of trials. Although earlier attempts have been made to secure "equal attention" to all the rows in an array, it is not clear that such a process can be operationally defined or measured.

The conclusion that Ss attempt to use anticipative strategies where these are applicable is also reinforced by the data on the distribution of guesses. When making whole reports, Ss preferred the middle or top lines of three-row arrays. For partial reports, when guessing accuracy was high, attention was given in equal proportion to all three rows as necessary for efficient reporting. When randomness was high and guessing accuracy, therefore, low, Ss overwhelmingly adopted the compromise strategy of attending to the middle row in the hope of picking up odd letters in either direction from the center. In other circumstances, Ss may sometimes increase their partial report scores by selecting vertical columns or other nonhorizontal segments of the display for attention (Holding, 1971, 1973).

The earlier experiment (Holding, 1970) also showed that letter accuracy decreased systematically as attention was directed away from the cued row. Deducing the direction of the S's attention from his predictive guesses is, of course, indirect, but the finding has been repeated with the use of two other methods (Holding, 1971). In one of these experiments, eye movements were measured with an infrared monitor; in the other, Ss were instructed where to direct their attention. Both these and the earlier guessing technique have defects of different kinds, although it is argued that each kind of defect has the effect of reducing the slope of the obtained curves. Nevertheless, all three sets of data show a rapid decline in the number of letters apparently available from nonattended rows as a function of the degree of spatial separation between attended and cued row, providing the most direct evidence possible that Ss are unable to return to a passive visual trace in order to retrieve extra information.

Althougin it is not possible to state categorically to what extent earlier work has been affected by cue anticipation, since randomization techniques have not usually warranted detailed description, the effects may be considerable. For example, in the Averbach and Coriell (1961) experiment, the 16 bar-marker positions were each sampled once during 16 trials. If, as their own data suggest, a $S$ in these conditions normally has access to over five letters, then once 11 positions have been eliminated he should be $100 \%$ correct on the rest; in addition, he should be approximately $30 \%$ correct on the earlier positions. In fact, calculating the exact probabilities for a diminishing pool of bar-marker positions shows that one can account for a total of 10.6 letters "available" on a chance basis, which is only a fraction less than the reported results. This estimate would be lower to the extent that Ss forget elapsed bar-marker positions, but higher to the extent that spatially selective guessing strategies are possible.

It is to be expected that, when care is taken to insure that cue sequences are unconstrainedly random, the differences between whole and partial reports should be largely abolished. This proved to be the case in four partial-whole comparisons by Holding (1972). American Ss, tested with three-row arrays of English and Arabic script, and Arab Ss, also tested with both scripts, all showed in partial report approximately one-third of the number of items in the corresponding whole reports, providing further evidence against the excess capacity hypothesis. Ss apparently have access to only three or four letters even when, as in the earlier experiments, the letters are familiar linguistic symbols.

A small residual difference between partial and whole reports in these and earlier experiments of this kind is undoubtedly due to output interference. The effect was first identified in the context of partial-whole comparisons by Anderson (1960), working with auditory digit sequences. In her experiment practices Ss showed an excess of proportional partial report over whole report in the amount of an estimated 9.9 available against 8.7 achieved in whole report. She concluded, not that $S$ s were consulting a stimulus trace in partial report, but that the whole reports were artificially depressed because "the act of writing the first digits of a message interferes with recall of the remaining digits in an immediate memory task [p. 219]."

The effects of output interference on visual memory have now been exhibited in detail by Dick (1971). In an earlier experiment concerned with decay effects (Dick, 1969), the results which appeared, despite relatively good cue randomization due to mixing partial report with whole report cues in a single sequence, were at first interpreted as favorable to the visual information storage hypothesis. However, the later paper replots these data, as well as newly obtained data, as a function of the serial position of response items. Accuracy decreases rapidly from the earlier to the later responses of each sequence. It is shown that the chances of any third response being correct are about one-half the chances of any first response, while the chances for any fifth response are halved again. Clearly, if one averages over all responses 
for whole report and over the earlier ones for partial report, the result will exhibit a spurious advantage for whole report.

Dick (1971), therefore, concludes that "selection does not occur in short-term visual memory [p. 263]." This is an unfortunate choice of terminology, since it is clearly possible to select among whatever items have been stored. In fact, when preselection is made possible by cue anticipation, Ss exhibit considerable flexibility in selective perception. Selectivity is clearly possible even when eye movements are precluded; Grindley and Townsend (1970) show that foreknowledge of the target confers an advantage in visual search with very brief exposures. Selectivity appears to be a separate issue, except when viewed as a property of subsequent access to a trace store. Instead, the evidence on output interference seems to limit severely the plausibility of earlier demonstrations of excess capacityt

When the effects of interference during recall are avoided by the use of recognition rather than recall procedures, the conclusion again seems to be that $\mathrm{Ss}$ have access to only a few letters. It has been shown (Holding, 1973) that $S s$ are unable to recognize a 12-letter array on over half of the instances when it is redisplayed a fraction of a second later. The estimates derived from this procedure and from comparable single-row recognitions suggest that no more than five letters are available; this is an upper bound, since these figures are almost certainly inflated by item guessing. The excess capacity hypothesis is, therefore, disconfirmed in several recent instances, while the earlier positive demonstrations all appear subject to either or both of the artifacts described above. From the evidence available, it seems reasonable to conclude that Ss have access to only three or four or, at the extreme, five letters and that excess capacity is not a feature of visual storage.

\section{Rapid Decay}

The evidence for rapid decay, although strictly irrelevant to the demonstration of visual information storage, has in practice been derived from the same experimental context. A common, but not universal, finding has been that the amount of information apparently available to $\mathrm{Ss}$ declines with delay in presenting the partial report cue. Thus, Sperling (1960) shows declines over times extending to the greater part of $1 \mathrm{sec}$ for row location cues, but not for color cuing, and Turvey and Kravetz (1970) obtained an effect up to $1 \mathrm{sec}$ for both location and letter shape cues.

On the other hand, Dick (1969) found an apparent superiority for partial report which was maintained over $850 \mathrm{msec}$; both partial and whole reports declined at the same rate, at least for color cues and probably for row location. The consistency of the partial-whole relationship in this study is quite compatible with the output interference explanation outlined above, since the interference caused by reporting is presumably constant regardless of the delay elapsing before report. Any constant difference found between whole and partial report would seem to indicate an output interference effect. However, the decay slope in this and earlier studies seems to demand a different explanation.

It should be borne in mind that the absolute amount forgotten during the delay period is fairly small, so that the effect should be regarded as posing only a minor problem for explanation. In work with three rows of symbols, the partial report score is normally multiplied by 3 in order to estimate the amount available. This procedure also increases the apparent slope of the decay curve by a factor of 3 , yielding an artificially dramatic decay function. In absolute terms, however, all that requires explanation is the loss of one or, occasionally, two letters. One possible hypothesis to account for the forgetting loss is that uncertainty about what is to be reported disrupts efficient rehearsal. A $\mathbf{S}$ who is attempting to hold an overload, while uncertain about what he will have to report, may lose items progressively as a result of inefficient or variable rehearsal strategies. Comparing Ss' performance when what is to be reported is uncertain with his performance when what is to be reported is known should, therefore, result in the familiar decay curve in the first case but a flat function in the second. A statistically significant difference of this kind has in fact been obtained (Holding, 1971).

The common decrease in partial report accuracy with delay of cue might, therefore, be due to rehearsal uncertainty rather than to the fading of a sensory trace. If uncertainty has this effect, a drop should also be observable at zero time delay and, in some circumstances, with whole report. Normally, when Ss know that they are to make whole reports, they are able to carry out appropriate selection and reinearsal of the material. In the case of Dick's (1969) experiment, however, partial and whole report cues were randomized together, leading to reporting uncertainty and apparently, therefore, to a progressive drop in whole report accuracy. The effect at zero time delay has been demonstrated by Holding (1971), who showed a significant difference between normal whole reporting and whole reporting into which uncertainty had been introduced by subsequently scoring each report on a random partial basis.

The uncertainty explanation seems therefore to have some predictive validity. However, it is clear that uncertainty is not the only relevant variable, if only because the delay effect does not always appear. When visual storage was tested by recognition rather than by recall (Holding, 1973), the equivalent of cue delay was represented by delays of $.25, .5$, or $1 \mathrm{sec}$ in presenting the recognition set. Under these circumstances there was, if anything, a tendency toward improvement with delay which yielded a nonsignificant decay effect. Most probably, the interaction between rehearsal uncertainty 
and reporting demands is critical, so that the single response required by recognition does not precipitate a loss in the way observed for the longer reports demanded by recall.

The data on the rapid decay of information appear to be inconsistent, while the interpretations which may be placed on the existing data are similarly variable. It is clear, however, that the research on rapid decay contributes little evidence which, in isolation, might be viewed as incontestable support for visual storage.

\section{Trace Storage}

It remains possible to argue that what is retained after a brief exposure, however limited, is retained in the form of a trace. It is unlikely that Ss have appreciable access to visual representations which are not verbally coded, since the Ss who could recall three to four Englisin letters could only reproduce less than a single Arabic character (Holding, 1972), presumably due to the absence of the linguistic equivalents normally used in encoding. However, it is possible that selected portions of a visual input, over very short time periods, may persist in a form which is in some way directly sensory, or at least comparatively peripheral. The difficulty here is not so much the existence of contrary evidence but the decision concerning what is meant by the hypotilesis and, thus, what evidence is relevant. If all that is intended is that the incoming stimuli "must be somewhere" while being processed, the hypothesis is either trivial or a covert reference to an implicit model of brain function. There is some doubt, for instance, whether the trace has a physiological status, defined by its relative neurological distance from the retina, or whether instead it has psychological status as an intervening variable.

In practice, several bodies of evidence seem to have been considered relevant. One set of data concerns backward masking, comprising studies in which later stimulation is shown to degrade the consequences of earlier stimulation. A full review of the complex literature on backward masking is beyond the scope of the present paper, although a search has been made for evidence which might appear to coerce the adoption of a trace storage hypothesis. Related topics are the summation of successive stimulation and the perceived duration of stimulation. In addition, there are studies which attempt to show that Ss have temporary access to information which appears more spatially or visually elaborate than migint otherwise be the case.

Sperling (1960) had found that a bright postexposure field decreased the number of letters available to partial report; in Sperling (1963) this field was replaced by a visual noise mask, which was thought to bring "erasure" of the visual image. The time elapsing before termination of the image by erasure was thought to provide a baseline for the determination of scanning rate. However, the erasure view is probably no longer tenable.
It is clear that the appearance produced by backward masking is qualitatively different from that produced by concurrent masking and that, at least in some circumstances, Ss are able to see the stimulus material "through" the mask (Liss, 1968). It is also true that visual information of a kind not susceptible to naming or verbal coding processes may be retained for relatively long periods, of the order of several seconds, despite the interposition of a masking field. Effects of this kind have been shown by Taylor (1969), by Phillips and Baddeley (1971), and by Mitchell (1972).

Current views of backward masking have been categorized as "interruption" theories or "integration" theories (Kahneman, 1968), with the balance of evidence probably favoring integration, or summation, views of short-delay masking. Eriksen and Eriksen (1971) presented three stimuli in succession to the same foveal location, finding that integration rather than erasure best accounted for the fact that all the stimuli were partially accessible. Coltheart and Arthur (1972) point out that, although Liss (1968) has argued for interuption, his finding that different masking patterns varied in effectiveness presumably arises because of target-mask integration making it differentially difficult to extract target from mask; similarly, although Spencer and Shuntich (1970) suggest that interruption occurs at delays of over $150 \mathrm{msec}$, the fact that masks of different energy levels give similar results is consistent with either theory, while the existence of forward masking is inconsistent with the interruption view.

It is probably the case that very different processes are operating on different time scales. Blank white masks give effects limited to the first $100 \mathrm{msec}$ which are presumably peripheral, since they only occur with ipsilateral presentation (Spencer, 1969). Contralateral, and thus presumably central, effects may be obtained with pattern masks over a much wider range of time intervals, depending upon the complexity of the stimulus array. Of course, variations due to the nature of the stimulus material also support the hypothesis of central involvement in tachistoscopic memory in experiments without masking. Mewhort, Merikle, and Bryden (1969) show better recall of material with second-order than with zero-order sequential dependencies, while Tulving, Mandler, and Baumal (1964) reported significant increments due to context. Presumably, what is contributed by central storage in these cases will also affect interpretation and report of material subjected to masking.

The recent review and experiments by Turvey (1973) strongly suggest that integration effects characterize true peripheral masking, which occurs over the first few tens of milliseconds after target offset. "Peripheral" here may refer not only to retinal effects but also to involvement of the lateral geniculate nuclei and even terminal cells in the striate cortex. In this type of masking, forward effects are at least as great as backward effects, and the 
amounts of stimulus energy critically determine the observed degradation of performance. Stimulus energy is not a critical variable in central, primarily backward masking, which appears to function in an interruption mode bearing a simple relationship to the onset-onset interval. Possibly central masking operates in parallel with, but on the output resulting from, peripheral masking; although the effects of central masking may be observed during the first $200 \mathrm{msec}$. In Scharf and Lefton's (1970) work, backward masking appeared to degrade information processing over a slightly longer interval, presumably as a result of central interference. However, even if these effects were peripheral and therefore relevant to the trace hypothesis, this order of time interval is considerably less than the period over which iconic effects are thought to have been observed.

The phenomenon of "unmasking" (Robinson, 1966), where a second subsequent stimulus apparently inhibits the effect of an earlier masking stimulus, appears at first sight unexplainable in terms of either interruption or integration. However, recent work by Barry and Dick (1972) seems to show that the effect only occurs in peripheral vision and is then due to the way in which Ss' reporting strategies deal with localized brightness reversals. If this is true, the phenomenon presents no difficulties for an integration theory of short-delay masking. A theory of sensory integration should further predict positive summation effects, in addition to degradation by masking, and a number of studies have provided verification.

It has been shown, for instance, that repeated presentations, and sometimes extended presentations, assist reporting of the stimulus materials. Jackson and Dick (1969) found that repeating the presentation of a single letter assisted in its recognition, the effect decreasing as separation of the two exposures increased to $60 \mathrm{msec}$. This relationship is consistent with an explanation in terms of sensory summation. However, Pylshyn (1965) had shown an opposite effect with letter and digit matrices, where increasing scores resulted from increasing separations ranging $20 \mathrm{msec}$ to $5 \mathrm{sec}$, attributing the effect to the advantage of increased processing time. Similarly, Smith and Carey (1966) found that fewer trials were needed to process rows of six letters as exposure times increased from 100 to $400 \mathrm{msec}$ and that two $20 \mathrm{msec}$ exposures separated by many of these intervals produced an effect parallel to the continuous exposures. Both of these findings conflict with Sperling's (1960) conclusion that visual information processing is unaffected by varying exposure duration up to $250 \mathrm{msec}$.

Attempts at direct measurement of perceptual persistence have been reported by Haber and Standing (1969). In a first experiment, Ss judged the continuity of simple forms repeatedly exposed by a moving slit or tachistoscope. Perceptual discontinuities appeared when the interval between exposures exceeded $250-300 \mathrm{msec}$, and $100 \mathrm{msec}$ longer under dark adapting-field conditions. The second experiment shows that apparent persistence is independent of exposure duration, but also that the same values occur for repeated stimulation of the same eye and for alternating between the eyes. Again, if the effect may be characterized as a central process, its relevance to the earlier Sperling model is dubious; of course, it is possible to argue that the information is held in a relatively unprocessed form, although at a central level, and that it thus constitutes a form of "trace." The Haber and Standing (1970) work provides a different measure, derived from two Ss' synchronization of click stimuli with the perceived offset of brief flashes. Persistence was found for all flash durations below $200 \mathrm{msec}$, a time estimate slightly longer but comparable to the durations apparent in peripheral masking.

The information contained in brief light flasines or simple shape stimuli is minimal, so that results from masking and other studies using simple material may not be directly applicable to more complex storage processes. A different kind of evidence, bearing directly upon the trace storage of letter material, is offered by Eriksen and Collins (1967). Dot patterns which together formed three-letter nonsense syllables were given a fragmentary initial presentation, followed by the complementary fragment at varying delay intervals. Ss seemed able to integrate successive presentations into correct syllables when the fragments followed closely in time, with performance falling to a minimum level by about $100 \mathrm{msec}$. This appears to constitute formidable evidence for brief information storage in visual form, although a methodological difficulty is that the stimulus set was heavily constrained. Only 20 syllables were used, and these were continuously available to the $S$ in the form of a printed list. The syllables were constructed from sets of only three initial, medial, and terminal letters, which provides many opportunities for Ss to extrapolate from partial cues. Thus, with the initial set of letters $T, V$, or $X$, if the $S$ sees any suggestion in the first fragment of an upper bar in the first letter position, the letter can only be $T$, and so forth. At best, the amount that is visually stored must be very much less than the 9 or 10 letters of the earlier hypothesis. A logical difficulty is that an essentially similar experimental procedure has been used (Stromeyer \& Psotka, 1970) in order to demonstrate "eidetic imagery" persisting over $24 \mathrm{~h}$. Clearly, two different processes cannot be demonstrated by the same means. However, both these objections are considerably weakened by the fact that performance in the experiment deteriorated rapidly, which is inconsistent with both the guessing and the eidetic mechanism explanations. The data must probably be taken as consistent with the occurrence of a very brief form of visual storage.

Evidence which seems to tell against directly visual storage over longer time intervals is presented by 
Holding (1973). An array of 3 by 4 letters, presented for $50 \mathrm{msec}$, was followed by another array after intervals of $250 \mathrm{msec}, 500 \mathrm{msec}$, or $1 \mathrm{sec}$. Ss used response keys to indicate those rows on the second array which had appeared on the first array. When single rows were repeated in the same position, a fading trace in that position should be reinforced by the new letter row, while traces of the other two rows sinould be masked by the new material. The repeated row should, therefore, stand out clearly while the trace persists, with a tendency to decline over time. When, on the other hand, a row is repeated in a different position in the second array, masking should occur between all the rows. Recognition of the transposed rows should not show a regular decline with time, since both the visual information and the masking effects will tend to decrease simultaneously. When all the rows are repeated in the same positions, the visual trace model should, of course, predict almost perfect recognition.

The experiment gave results which were contrary to all of these predictions. There was no difference in accuracy of recognition between the transposed rows and those reappearing in the same positions and no differences in the time course of recognition. All conditions showed an apparent but not significant increase, rather than the predicted decrease, as the interval between stimulus array and recognition array was lengthened. Ss were not reliably able to recognize when the entire array was repeated and the data, when corrected for guessing, suggested that they had access to about four letters. This conclusion was strengthened by the analysis of response times. Shorter times appeared when the $S$ correctly recognized a single row or when only a single row was recognized, while longer times occurred in conditions where responding appeared to be based upon inference, suggesting that only single rows were directly seen. The crucial result for the present purpose is that the effects of row transposition gave no support to the visual trace hypothesis.

Surveying the evidence on visual persistence seems to lead to the tentative conclusion that any positive effects are limited to an extremely short time period following stimulation. By the time $250 \mathrm{msec}$ have elapsed, other nonvisual processes are well established. Before that time, for a period of the order of $100 \mathrm{msec}$ or a little longer, depending upon stimulus and adapting field conditions, relatively small amounts of information or simple stimulation may persist in a form little changed from the original input. In the experiments which seem to show this effect, the $\mathrm{S}$ has preselected or fixated the appropriate display area rather than reexamined a broader trace. At this first stage, responses to the input may be substantially modified by presenting subsequent superimposed or adjacent stimuli; Weisstein (1966), for example, finds a peak in the masking function for four-letter stimuli at $50 \mathrm{msec}$ with arrow indicators and at about $70 \mathrm{msec}$ for eight-letter displays. Also at this stage, Ss may give extended estimates of stimulus duration and may perhaps be able to summate fragmentary presentations into complete visual units. At the later stage, a number of things may be occurring at different levels of input processing. The following section briefly indicates the kinds of hypotheses which have been put forward to account for more complex processing.

\section{Related Issues}

Supplementing the earlier model, Sperling (1963, 1967) has proposed that iconic data are fed into an intermediate store whose function is to program acoustic transformations for longer term auditory storage. There is no direct evidence for such an intermediate store, which is postulated in order to explain the discrepancy between the rate at which items can be named and the apparent rate of uptake of $10 \mathrm{msec} /$ item derived from the Sperling (1963) masking study. Using a higher energy mask sufficient to obscure all target letters when presented simultaneously, Merikle, Coltheart, and Low (1972) have obtained a modified curve for letters reported as a function of exposure time. The first three or four letters are retained for report as exposure duration increases by $30 \mathrm{msec} / \mathrm{item}$, the retention curve then flattening abruptly after $100 \mathrm{msec}$. Mackworth (1963) earlier reported dual slopes obtained from visual presentation as evidence for separate storage mechanisms.

The dual slope of the curve is explained by Coltheart (1972) as the resultant of two simultaneous processing functions, visual encoding and naming. Visual encoding provides a low capacity with retarded decay, but is accomplished rapidly until the limit of three or four letters is reached. The naming process begins at the same time to transfer information more slowly to verbal (acoustic) storage and may continue to do so for at least $1 \mathrm{sec}$. The two functions together offer a good fit to the exposure time data and provide a qualitative explanation for the Scarborough (1972) finding that a prior auditory load has a greater effect on memory for long $(750 \mathrm{msec})$ than for shorter (250 msec) visual displays, since only the longer display could result in appreciable auditory coding. Similarly, Den Heyer and Barrett (1971) find that item position, presumably visually coded, is impaired by a subsidiary visual task and that item identity, presumably auditorily coded, is impaired by a verbal subtask. However, when Henderson (1972) imposed a prior auditory memory load or a prior spatial location load, the impairment was slight and did not vary differentially as a function of acoustic confusability; the conclusion was reached that an auditory-verbal loop could not play a mandatory role in coding and storage of visual information.

The relation between the visual encoding mechanism of Coltheart (1972) and the visual vs name codes of Posner, Boies, Eichelman, \& Taylor (1969) remains 
obscure, as does the relation of both to iconic storage. The decay of visual codes as measured by same-different judgments of letters of the same name or typographical case appears to be variable over longer intervals of the order of many seconds. The capacity of this kind of storage appears to be limited to three or four items which, however, in the light of the earlier discussion of "excess capacity," no longer serve to differentiate the visual code from apparent iconic effects. Other work appears to coalesce the properties of the shorter and longer term visual storage mechanisms. Thus, Shaffer and Shiffrin (1972) are impelled to abandon the rigid distinction between the sensory register of the earlier Atkinson and Shiffrin (1968) model and its active rehearsal counterpart, in view of their data on the successive presentation of picture material. Exposure time, up to $2 \mathrm{sec}$, made a great difference to visual recognition but blank time betweep pictures, during which visual rehearsal or decay effects might have come into play, did not.

Another link between short- and long-term effects is provided by data on unnameable shapes. What Mitchell (1972) shows is that visual information provided by single nonsense forms, despite brief exposure, may survive a pattern mask for at least $6 \mathrm{sec}$. In a first experiment, repeated presentation of each Gibson figure might have provided the opportunity for the $S$ to form a "visual prototype," but a second experiment used each figure only once. Since same-different judgments remained appreciably above chance over a period which may be extrapolated to $11 \mathrm{sec}$, it appears necessary to postulate a short-term visual store with slow decay, which can utilize information presented for as short a period as $20-40 \mathrm{msec}$. Such a store might take the form of a noniconic, but nevertheless visual, buffer and might share common features with the short-term visual store, operating over $25 \mathrm{sec}$ or more, of Kroll, Parks, Parkinson, Bieber, and Johnson (1970). It is clearly undesirable to entertain a proliferation of postulated stores, although at the present stage of research there is still probably insufficient evidence to allow the development of explicit and economical explanations.

\section{AUDITORY STORAGE}

\section{Excess Capacity}

It might be expected that auditory trace effects in a primarily temporal modality would be more easily demonstrated than iconic effects. As indicated above, Anderson (1960) obtained a difference between partial and whole report scores for recall of sequences of 12 auditory digits presented at a rate of $2 / \mathrm{sec}$. The difference was small and was attributed to output interference, as stated. After trying recall techniques, which failed to show any consistent evidence of an echoic trace under their conditions, Treisman and Rostron (1972) used a recognition procedure with pure tone stimuli; this obviates the output interference problem, although guessing biases pose problems of interpretation. These investigators interpreted the results as favorable to the echoic hypothesis, but the method does not yield a direct estimate of the amount of information available to the $S$ and does not, therefore, address the issue of excess capacity.

A set of experiments explicitly designed as an analog of the Sperling procedure was performed by Darwin, Turvey, and Crowder (1972). Some of the results seemed positive, with partial reports by spatial location scoring proportionately higher than whole reports; this effect was small, with an estimate of about five letters available in partial vs about four in whole report, depending upon the indicator delay. When partial reporting was based on selecting digits vs letters, it was only superior to whole report if the information on correct location of the items was neglected. In order to explain a comparable failure of digit/letter partial reports described earlier in this review, it was suggested that the digit/letter choice did not afford the same opportunities as reporting by spatial location for the $S$ to make use of selective cue anticipation. The design of the experiment was not such as to rule out output interference effects, nor the kinds of guessing bias identified in the visual experiments.

The most satisfactory way of reducing the anticipation of cues is not only to randomize without constraint but also to increase the ensemble of guessing choices by grouping whole report cues and partial report cues together, rather than presenting them as separate conditions. Combined randomization was employed by Holding, Foulke, and Heise (1973), with results clearly unfavorable to the hypothesis of excess echoic storage. On the grounds that the long time span associated with digit presentation at normal rates might make for an unsuitable test of a fading echoic trace, these investigators had recourse to compressed speech techniques. Digit strings of Length $6,8,10$, or 12 were presented at a rate of $12 / \mathrm{sec}$, half into each ear, and Ss were cued by ear location for partial recall. Both whole and partial recall (doubled) showed about three digits available, and there was no interaction with list length. When, in a second experiment, spaces were inserted between the digits, the number of digits reported rose in both report conditions despite the increased time delay. The rise, not predicted by any simple form of trace theory, ought to increase the tendency to output interference, which presumably accounted for the minor ( 0.2 digits) inferiority of whole vs partial reports.

As in the case of the visual data, what evidence has been accumulated seems to tell against the hypothesis that echoic storage may be distinguished in terms of its storage capacity. The twin mechanisms of output interference and selective guessing are probably sufficient to explain the existing positive evidence, while the latest experiment is negative. 


\section{Rapid Decay}

Scant evidence bears upon the decay question. Anecdotally, there is little doubt that one can readily reimage elapsed sounds at appreciable delays after stimulation, but this is presumably a separate issue. The Darwin et al (1972) study shows a decline of about one-half an item over $4 \mathrm{sec}$, which must be regarded as a minor effect, but also a strong recency effect in that the last reported of three items was significantly better reported than the previous two. However, as the authors indicate, a recency effect may be due either to the effects of decay or to interference with a prior by a later item.

The Holding et al (1973) data yielded serial position curves mainly exhibiting primacy rather than recency effects. More important, however, are the improved results from introducing silent spaces between successive digits, which contraindicate decay effects. If, as might be argued instead, the massing of digits in the first experiment gives rise to a backward masking effect on the sensory trace, the spacing introduced in the second experiment should reduce this effect and, thus, allow the superiority of partial report to appear. However, if Aaronson (1967) is correct in suggesting that interpolated silent time is needed to facilitate serial perceptual processing, an improvement should be detectable in both whole and partial conditions. The latter was, of course, the obtained result.

\section{Trace Storage}

A number of overlapping theories have incorporated trace storage features into accounts of auditory perception. Neisser (1967), modifying Sperling (1963), has used the term "echoic storage" with reference to a variety of auditory phenomena; Crowder and Morton (1969) have promulgated "precategorical acoustic storage," which is at least superficially similar at the level of linguistic digit memory; Massaro $(1970,1972)$ has appealed to "preperceptual auditory images," initially to account for tonal recognition. The evidence for each of these constructs is limited and indirect.

In the case of the preperceptual image, the basic finding is that performance in classifying a brief, pure tone stimulus as "high" or "low" is impaired by a later masking tone. Since the curve relating the backward masking effect to interstimulus interval shows that impairment ceases at about $250 \mathrm{msec}$, this figure is taken to represent the duration of the postulated image. The effect is presumably central, since Massaro (1970) finds backward masking by contralateral stimuli, as well as masking by tones at frequencies well removed from the pitch of the stimulus tone. Of course, the existence of backward masking in no way coerces the adoption of an auditory image hypothesis, but may instead represent a form of interference with judgmental processes carried out upon an already transformed auditory input.
In fact, the slope of the decay function varies widely as the masking and test parameters are changed (Loeb \& Holding, in press). The same data, obtained in a two-tone comparison paradigm of the Elliott (1970) type, show that backward masking effects are far stronger when the masking tone follows whichever is the variable tone in the comparison, regardless of whether it or the standard tone is presented first or second. When a mask follows the first presented tone, it is reasonable to postulate that the masking effect is due to disrupting a storage mechanism, which could take the form of a trace. However, this is not the case when the mask follows the second tone, as there is no longer a storage requirement, and it becomes more plausible to assume that the "mask" is an interference effect operating on the judgmental process initiated by the variable tone. For the sake of parsimony, the same explanation might be applied to masks inserted after the first tone, except that white noise in this position is less effective than when inserted after both tones have been presented (Holding, Loeb, \& Yoder, 1972), which suggests the possibility that the two "backward masking" effects are produced by different mechanisms. On the other hand, even if a mask in the first position was interfering with a storage process, further evidence would be needed to show that a simple trace was involved.

The precategorical acoustic storage hypothesis relies mainly upon the effect of a redundant suffix on the serial position curve for recall of sequences of digits. Since the suffix increases errors at the more recent positions, Crowder and Morton (1969) argue that it overwrites the traces of the immediately prior digits. However, there is some effect on errors at all positions, which is inconsistent with the argument, while, as Treisman and Rostron (1972) point out, it is difficult to justify the advantages of prolonging the readout potential for as long a period as 2 or more sec. In any case, the proposed store is not literally precategorical and is, therefore, of dubious relevance to the present issue. Since nonspeech suffixes like a buzzer or speech sounds mismatched to the stimuli abolish or reduce the suffix effect (Crowder, 1971), provision has to be made for the initial encoding of stored material in terms of at least physical features.

Similar problems arise at the level of simple pitch perception, where the masking sound appears to have the same function as the suffix. Using the Massaro (1970) paradigm, it has been shown that white noise, which physically brackets a tonal stimulus, produces little or no backward masking, while pure tones, even when remote from the stimulus frequency, mask as heavily as do similar tones (Holding \& Loeb, 1973). Presumably the noise is classified as perceptually "different" and, thus, does not interfere, while the stimulus and pure tone masks fall into the same perceptual category and do interfere. The implication is 
that the apparent masking effect, even at the tonal level, is neither "precategorical" nor "preperceptual." In any case, recent work by Leshowitz and Cudahy (1973) seems to show that these backward masking effects are almost completely eliminated by extended practice, again implying that there is no direct sensory effect.

The most direct form of evidence for auditory trace phenomena comes, as with the visual evidence, from experiments on noninformative stimuli. Efron (1970), varying the Haber and Standing (1970) procedure by having Ss match the onset of a light to the perceived offset of a sound, has shown that the perceived duration of shorter stimuli remains constant at about $130 \mathrm{msec}$. Although, as Massaro (1972) suggests, this technique may be subject to a decision bias, the work of Plomp (1964) is not. This study shows that a silent interval between noise bursts is undetected when the second burst is softer over times varying from 2 to $78 \mathrm{msec}$, depending upon the loudnesses employed. It seems clear, therefore, that some persistence of simple stimuli occurs over a period of the order of $100 \mathrm{msec}$.

\section{CONCLUSIONS}

There is not the slightest doubt that any attended stimulation will leave a residue of neural processes which persist in some form for longer than the original stimulation. As Sperling (1960) points out, information in successive saccades is integrated to form a continuous visual world. The question is whether the postulated extra entities, the varieties of sensory store, are meaningful and verifiable explanatory constructs. It has been shown that, when the evidence relating to the hypothetical features of sensory storage is closely examined, most of the properties which seemed heuristically valuable appear to be unsupported.

In both vision and audition there is good evidence that simple forms of stimulation persist, but for periods far shorter than are considered useful for most forms of sensory storage hypothesis. With informative stimuli the evidence is less clear, although it seems probable that by about $250 \mathrm{msec}$ after stimulation other processes have come into play. It remains dubious to what extent the persistence of information is of a directly sensory nature, owing to problems of both definition and fact. The degree of persistence that has been established is limited to the normal span of attended stimuli. There appears to be no conclusive support for what must be regarded as the most prominent distinguishing feature of sensory storage theory: the suggestion that a trace, image, or primitive store bears an excess of information which can be accessed at a delay after stimulation. Those instances which appear positive have not explicitly controlled for output interference or anticipatory selective guessing, or both. Studies in which these effects have been controlled have yielded negative results.
No alternative broad theory is offered, but these conclusions attempt to lay the groundwork upon which theory reconstruction may begin. Sifting the evidence in order to establish what is known and what is not known seems to be a necessary activity at this stage in an area where speculation has run far ahead of the available facts. Eventually, analysis of the input side of the organism will undoubtedly reveal a complex of serial, parallel, and cascaded processes. Although issue has been taken with some of the interpretations offered, most of the studies reviewed above report findings which are useful in their own right as part of the factual substrate necessary for such analysis. What it is necessary to doubt is whether the final block diagram will contain any single feature labeled "sensory storage."

\section{REFERENCES}

Aaronson, D. Temporal factors in perception and short-term memory. Psychological Bulletin, 1967, 67, 130-144.

Anderson, N. S. Poststimulus cuing in immediate memory. Journal of Experimental Psychology, 1960, 60, 216-221.

Atkinson, R. C., \& Shiffin, R. M. Human memory: A proposed system and its control processes. In $K$. W. Spence and J. T. Spence (Eds.), The psychology of learning and motivation: Advances in research and theory. Vol. 2. New York: Academic Press, 1968.

Averbach, E., \& Coriell, A. S. Short term memory in vision. Bel Systems Technical Journal, 1961, 40, 309-328.

Averbach, E., \& Sperling, G. Short-term storage of information in vision. In C. Cherry (Ed.), Information theory: Proceedings of the fourth London symposium. London: Butterworth, 1961.

Barry, S. H., \& Dick, A. O. On the "recovery" of masked targets. Perception \& Psychophysics, 1972, 12, 117-120.

Bricker, P. D., \& Chapanis, A. Do incorrectly perceived tachistoscopic stimuli convey some information? Psychological R eview, 1953, 60, 181-188.

Broadbent, D. E. A mechanical model for hum an attention and immediate memory. Psychological Review, 1957, 64, 205-215.

Clark, S. E. Retrieval of color information from the pre-perceptual storage system. Journal of Experimental Psychology, 1969, 82, 263-266.

Coltheart, M. Visual information-processing. In P. C. Dodwell (Ed.), New horizons in psychology. Vol. 2. London: Penguin, 1972 .

Coltheart, M., \& Arthur, B. Evidence for an integration theory of visual masking. Quarterly Journal of Experimental Psychology, 1972, 24, 262-269.

Crowder, R. G. Waiting for the stimulus suffix: Decay, delay rhythm and readout in immediate memory. Quarterly Journal of Experimental Psychology, 1971, 23, 324-340.

Crowder, R. G., \& Morton, J. Precategorical acoustic storage (PAS). Perception \& Psychophysics, 1969, 5, 365-373.

Darwin, C. J., Turvey, M. T., \& Crowder, R. G. An auditory analogue of the Sperling partial report procedure. Cognitive Psychology, 1972, 3, 255-267.

Den Heyer, K., \& Barrett, B. Selective loss of visual and verbal information in STM by means of visual and verbal interpolated tasks. Psychonomic Science, 1971, 25, 100-102.

Dick, A. O. Relations between the sensory register and short-term storage in tachistoscopic recognition. Journal of Experimental Psychology, 1969, 82, 279-284.

Dick, A. O. On the problem of selection in short-term visual (iconic) memory. Canadian Journal of Psychology, 1971, 9 , 250-263.

Doost, R., \& Turvey, M. T. Iconic memory and central processing capacity. Perception \& Psychophysics, 1971,9, 269-274.

Efron, R. Effect of stimulus duration on perceptual onset and offset latencies. Perception \& Psychophysics, 1970, 8, 231-234.

Elliott, L. L. Pitch memory for short tones. Perception \& Psychophysics, 1970, 8, 379-384.

Eriksen, C. W., \& Colegate, R. L. Selective attention and serial processing in briefly presented visual displays. Perception \& Psychophysics, 1971, 10, 321-326. 
Eriksen, C. W., \& Collins, J. F. Some temporal characteristics of visual pattern perception. Journal of Experimental Psychology, 1967, 74, 476-484.

Eriksen, C. W., \& Eriksen, B. A. Visual perceptual processing rates and backward and forward masking. Journal of Experimental Psychology, 1971, 89, 306-313.

Eriksen, C. W., \& Steffy, R. A. Short-term memory and retroactive interference in visual perception. Journal of Experimental Psychology, 1964, 68, 423-434.

Glanville, A. \& Dallenbach, K. M. The range of attention. American Journal of Psychology, 1929, 41, 207-236.

Grindley, G. C., \& Townsend, V. Visual search without eye movement. Quarterly Journal of Experimental Psychology, $1970,22,62-67$.

Haber, R. N., \& Standing, L. G. Direct measures of short-term visual storage. Quarterly Journal of Experimental Psychology, $1969,21,4354$.

Haber, $\dot{R}$. N., \& Standing, L. G. Direct estimates of the apparent duration of a flash. Canadian Journal of Psychology, 1970, $24,216-229$.

Henderson, L. Spatial and verbal codes and the capacity of STM. Quarterly Journal of Experimental Psychology, 1972, 24, 485-495.

Holding, D. H. Guessing behavior and the Sperling store. Quarterly Journal of Experimental Psychology, 1970, 22, 248-256.

Holding, D. H. The amount seen in brief exposures. Quarterly Journal of Experimental Psychology, 1971, 23, 72-81.

Holding, D. H. Brief visual memory for English and Arabic letters. Psychonomic Science, 1972, 28, 241-242.

Holding, D. H. Recognition tests of visual information storage. British Journal of Psychology, 1973, 64, 9-16.

Holding, D. H., Foulke, E., \& Heise, R. L. Brief storage of compressed digits. Journal of Experimental Psychology, 1973, 101, 30-34.

Holding, D. H., \& Loeb, M. Postcategorical masking by tones or noise. Paper read at meeting of Psychonomic Society, St. Louis, 1973.

Holding, D. H., Loeb, M., \& Yoder, D. "Masking" versus interference in pitch perception. Journal of Auditory Research, 1972, 12, 247-254.

Jackson, R. H., \& Dick, A. O. Visual summation and its relation to processing and memory. Perception \& Psychophysics, $1969,6,13-15$.

Kahneman, D. Method, findings and theory in studies of visual masking. Psychological Bulletin, 1968, 70, 404-426.

Keele, S. W. \& Chase, W. G. Short-term visual storage. Perception \& Psychophysics, 1967, 2, 383-386.

Kroll, N. E. A., Parks, T., Parkinson, S. R., Bieber, S. L., \& Johnson, A. Short-term memory while shadowing: Recall of visually and of aurally presented words. Journal of Experimental Psychology, 1970, 85, 220-224.

Leshowitz, B., Cudahy, E. Frequency discrimination in the presence of another tone. J ournal of the Acoustical Society of America, 1973, 54, 882-887.

Liss, P. Does backward masking by visual noise stop stimulu processing? Perception \& Psychophysics, 1968, 4, 328-330.

Loeb, M., \& Holding, D. H, Delayed interference in pitch judgments. Journal of Auditory Research, in press.

Mackworth, J. F. The visual image and the memory trace Canadian Journal of Psychology, 1962, 16, 55-59.

Mackworth, J. F. The duration of the visual image. Canadian Journal of Psychology, 1963, 17, 62-81.

Massaro, D. W. Preperceptual auditory images. Journal of Experimental Psychology, 1970, 85, 411-417.

Massaro, D. W. Preperceptual inages, processing time, and perceptual units in auditory perception. Psychological $R$ eview, $1972,79,124-145$.

Merikle, P. M., Coltheart, M., \& Lowe, D. G. On the selective effects of a patterned masking stimulus. Canadian Journal of Psychology, 1971, 25, 264-279.

Mewhort, D. J. K., Merikle, P. M., \& Bryden, M. P. On the transfer from iconic to short-term memory. Journal of Experimental Psychology, 1969, 81, 89-94.

Mitchell, D. C. Short-term visual memory and pattern masking. Quarterly Journal of Experimental Psychology, 1972, 24, 394-405.

Neisser, U. Cognitive psychology. New York: A ppleton-Century-Crofts, 1967.

Phillips, W. A., \& Baddeley, A. D. Reaction time and short-term visual memory. Psychonomic Science, 1971, 22, 73-74.

Plomp, R. Decay of auditory sensation. Journal of the Acoustical Society of America, 1964, 36, 277-282.

Posner, M. I. Abstraction and the process of recoghition. In J. T. Spence and G. Bower (Eds.), The psychology of learning and motivation. Vol. 3. New York: Academic Press, 1969.

Posner, M. I., Boies, S. J., Eichelman, W. H., \& Taylor, R. L. Retention of visual and name codes of single letters. Journal of Experimental Psychology Monograph, 1969, 79(1, Part 2).

Pylshyn, $Z$. W. Information available from two consecutive exposures of visual displays. Canadian Journal of Psychology, $1965,19,133-144$.
Robinson, D. N. Disinhibition of visually masked stimuli. Science, 1966, 154, 1335-1336.

Rumelhart, E. D, A multi-component theory of the perception of briefly exposed visual displays. Journal of Mathematical Psychology, 1970, 7, 191-218.

Scarborough, D. L. Memory for brief visual displays: The role of implicit speech. Cognitive Psychology, 1972, 3, 289-297.

Scharf, B., \& Lefton, L. A. Backward and forward masking as a function of stimulus and task parameters. Journal of Experimental Psychology, 1970, 84, 331-338.

Shaffer, W. O., \& Shiffrin, R. M. Rehearsal and storage of visual information. Journal of Experimental Psychology, 1972, 92, 292-296.

Smith, F., \& Carey, P. Temporal factors in visual information processing. Canadian Journal of Psychology, 1966, 20, 337-342.

Spencer, T. J. Some effects of different masking stimuli on iconic storage. Journal of Experimental Psychology, 1969, 81, 132-140.

Spencer, T. J., \& Shuntich, R. Evidence for an interruption theory of backward masking. Journal of Experimental Psychology, 1970, 85, 198-203.

Sperling, G. The information available in brief visual presentations. Psychological Monographs, 1960, 74(11).

Sperling, G. A model for visual memory tasks. Human Factors, $1963,5,19-31$

Sperling, $G$. Successive approximations to a model for short-term memory. A cta Psychologica, 1967, 27, 285-292.

Steffy, R. A., \& Eriksen, C. W. Short-term perceptual recognition memory for tachistoscopically presented nonsense forms. Journal of Experimental Psychology, 1965, 70, 277-283.

Stromeyer, C. F., \& Psotka, J. The detailed texture of eidetic images. Nature, 1970, 225, 1267-1268.

Taylor, R. L. Comparison of short-term memory and visual sensory analysis as sources of information. Journal of Experimental Psychology, 1969, 81, 515-522.

Treisman, M., \& Rostron, A. B. Brief auditory storage: A modification of Sperling's paradigm applied to audition. Acta Psychologica, 1972, 36, 161-170.

Tulving, E., Mandler, G., \& Baumal, R. Interaction of two sources of information in tachistoscopic word recognition. Canadian Journal of Psychology, 1964, 18, 62-71.

Turvey, M. T. Repetition and the preperceptual information store. Journal of Experimental Psychology, 1967, 74, 289-293.

Turvey, M. T. On peripheral and central processes in vision. Psychological R eview, 1973, 80, 1-52.

Turvey, M. T., \& Kravetz, S. R etrieval from iconic memory with shape as the selection criterion. Perception \& Psychophysics, $1970,8,171-172$.

Von Wright, J. M. Selection in visual immediate memory. Quarterly Journal of Experimental Psychology, 1968, 20, 62-68

Weisstein, N. A. Backward masking and models of perceptual processing. Journal of Experimental Psychology, 1966, 72, 232-240.

Wickelgren, W. A., \& Whitman, P. T. Visual very-short-term memory is nonassociative? Journal of Experimental Psychology, 1970, 84, 277-281.

(Received for publication May 3,1974 ; accepted May 25, 1974.)

\section{EDITORS' COIIMENT}

The editorial review process for the preceding article by Dennis Holding included a reading by one of the regular Consulting Editors, Max Coltheart. The latter took detailed exception to the Holding interpretation of the literature, but he recognized the educational benefit of publishing the manuscript if it were followed by a response. The next paper is a response by Dr. Coltheart, and it is followed by a brief rejoinder from Dr. Holding.

As Editors we recognize that on occasion a public exchange of views, such as that in the present series, is an appropriate use of journal space. In most cases, however, we believe the best forum for scholarly criticism is the well conceived series of experiments that address an issue of controversy. 